\title{
DE PALACIOS Y PASADIZOS: UN ELEMENTO OLVIDADO DE LA ARQUITECTURA SEVILLANA
}

RAFAEL CÓMEZ

Se realizaba el traslado de los libros de la Biblioteca Colombina. El joven se apoyó en la librería y el mueble cedió inesperadamente, abriéndose como una puerta. Como en un cuento de misterio, el protagonista se sintió en otro ámbito, en un espacio estrecho y oscuro. Un pasillo le conducía a otra parte. Prendió el encendedor y por un momento se disiparon las tinieblas. Al fondo, una puerta que abría a la torre, la Giralda; aparecía cegada. Había descubierto un pasadizo. Un pasadizo secreto, hasta ahora ignorado por todos.

Claro es que se trataba de un pasadizo interior, como tantos que hubo en los palacios españoles. Sin embargo, el pasadizo como elemento arquitectónico exterior, conformando el espacio externo del edificio y sirviendo como vaso comunicante entre un palacio y un templo, no fue menos frecuente en el contexto de la arquitectura renacentista sevillana, perdurando hasta el siglo XVIII en que se construyen los últimos ejemplos. Ahora bien, ¿cuál era su origen?, ¿cuál su finalidad?, ¿cuál su significado?

Si nos remontamos al que tipológicamente parece el más antiguo de todos los pasadizos sevillanos --del que sólo nos resta memoria a través del dibujo de Richard Ford - sus comienzos pueden datar de fines de la Edad Media. Tal el caso del palacio del marqués de la Algaba, que comunicaba con la cabecera de la iglesia parroquial de Omnium Sanctorum sin que los señores tuvieran que bajar a la calle. El palacio, hoy día en ruina, ostenta la mejor portada mudéjar de la arquitectura civil sevillana.

Pero hubo además otros de los que sólo nos quedan meras noticias en las crónicas hispalenses. Próxíma a la parroquia de San Martín vivían los Saavedra, cuya casa conectaba con la iglesia donde poseian tribuna propia. Asimismo, Jos duques de Alcalá contaban también con una tribuna en la parroquial de San Esteban, a la que accedian por pasadizo desde su espléndido palacio, conocido como Casa de Pilatos. ${ }^{2}$

1 B. Ford, Richard Ford en Sevilla, con notas de D. Angulo, Madrid, 1963, lám. 35, p. 40. Vid también A. Sancho Corbacho, Iconografiza de Sevilla, Sevilla, 1973.

2S. Montoto, Sevilla en el Imperio (siglo XVI), Sevilla, 1973, pp. 199-200; V. Lleó, Nueva Roma. Mitología y Humanismo en el Renacimiento sevillano, Sevilla, 1979, p. 34. Vid un intento de clasificación de portadas en D. Oliva, "De arquitectura doméstica sevillana en el siglo XVI", Homenaje al Dr. Hernándeq Díaz, I. Sevilla, 1982, pp. 231-241. 
Esta simbiosis entre el templo y el palacio, esta convivencia de lo sagrado y lo profano en un asociacionismo histórico debemos contemplarla en el contexto de una sociedad cuyo estamento más alto, la nobleza, no sólo tenia enterramientos, fundaciones piadosas y capellanias en las parroquias, sino también el privilegio real heredado de la Edad Media, de defender los templos parroquiales. Ello dio origen a que en las luchas entre familias nobiliarias - sobre todo entre los Guzmán y los Ponce de León- se fortificaran en las iglesias, combatiendo desde las torres, como hicieran los boloñeses desde las altas torres de sus palacios. ${ }^{3}$

Sin que pretendamos establecer un catálogo de pasadizos en las breves páginas que siguen, hemos de señalar que no pocos de estos elementos debieron existir asimismo en la provincia, aunque lamentablemente hayan desaparecido. Cabe preguntarse si el destruido palacio de los duques de Arcos en Marchena no conectaría del mismo modo con la vecina parroquia de Santa María de la Mota - donde poseían hermosa tribuna y el patronato sobre su capilla mayor-, situada en el corazón de la antigua alcazaba y dentro del magnífico conjunto palacial. ${ }^{4}$ Ya en la provincia de Cádiz, la parroquia mudéjar de Santa María de la $O$, en Sanlúcar de Barrameda, cuenta con otra espléndida tribuna, encontrándose muy próximo el palacio de los duques de Medina Sidonia, patronos del templo.

Aparte estos conjuntos palaciales cuyos orígenes remiten a la Edad Media y cuya articulación sería difícil de precisar hoy día, dentro de la provincia de Sevilla podemos mencionar otros dos conjuntos en los que claramente se define la fusión entre el templo y el palacio, aunque ambos tengan distinto carácter.

En primer lugar, el conjunto de la plaza mayor de la villa de Olivares, cuyos lados mayores ocupan la colegiata y el palacio ducal. Éste fue edificado a mediados del siglo XVI por el primer Conde de Olivares, don Pedro de Guzmán, mientras que la colegiata fue dotada por el Conde.Duque, don Gaspar de Guzmán, en 1623. La plaza, de planta rectangular, estuvo abierta en los extremos por arcos que a modo de calles "encubiertas" ligaban el conjunto de edificios que la constituyen, hallándose la propia iglesia colegial adherida al alfolí o pósito por medio de una calle de aquel tipo.

El templo, comenzado en la primera mitad del siglo XVII y en el que parecen haber intervenido los arquitectos Vermondo Resta y Sebastián de Ruesta, ${ }^{5}$ presenta tribunas con celosías sobre el presbiterio, destinadas a que los Duques pudiesen asistir a los oficios litúrgicos desde un lugar pre-

${ }^{3}$ S. Motitoto, op. cit., pp. 202-203.

4 V. A., Inventario Artístico de Sevilla y su provincia, II, Madrid, 1985, p. 16

${ }^{5}$ V. A., Inventario ertístico de Sevilla y su provincia, I, Madrid, 1982, p. 581. 
minente y sin necesidad siquiera de ser vistos, en la evocación lejana de un mínimo Escorial andaluz. Una de las tribunas pisa la bóveda de la capilla de las Reliquias, situada en el lado del Evangelio, que contiene ochenta relicarios de diferentes formas colocados en estanterías que cubren las paredes; traídas de las catacumbas de Roma en 1590, con licencia del Papa Gregorio VIII a instancias del Conde don Enrique, y colocadas allí en $1658 .^{\circ}$

Finalmente, el magnífico conjunto del palacio arzobispal de Umbrete, construido en el siglo XVII y reformado en 1735 por el arquitecto Diego Antonio Díaz, muestra un grandioso arco cuyo pasadizo ha desaparecido y que lo une a la hermosa iglesia parroquial de Nuestra Señora de la Consolación, edificada por el mismo maestro por los mismos años. ${ }^{7}$ El efecto, que recuerda remotamente el producido por el arco que une el palacio arzobispal con la catedral de Toledo, se convierte en un acierto urbanístico al enlazar el palacio veraniego de los arzobispos sevillanos con la cabecera de la iglesia creando un gran arco trianfal de acceso a la plaza mayor de Umbrete, en una de las más brillantes realizaciones del gran mecenas arzobispo don Luis de Salcedo y Azcona. ${ }^{8}$

Un análisis desapasionado del peculiar elemento que ocupa nuestra atención nos lleva a considerar su indiscutible origen musulmán, ya que es en las ciudades del mundo islámico donde aparecen estas calles cubiertas que tanto arraigo tuvieron en nuestra urbanística. Los arcos de entibo entre un edificio y otro, a veces, se hacen más anchos, llegando a tal grosor que quedan como arcos de un puente; en este caso, esa superficie puede servir de vivienda o de pasadizo?

El califa de Córdoba llegaba desde su palacio a la macsura de la mezquita, sin salir a la calle, a través de un pasadizo, sin ser visto ni molestado. Esta penetración del poder civil en la esfera religiosa, que se hace concreción plástica en el campo de la arquitectura, se convierte en norma con la llegada del absolutismo monárquico de los tiempos modernos. El origen medieval de muchos de nuestros palacios y alcázares fomentó la pervivencia de este elemento hispano-musulmán, que se convertiria en elemento

'J. Gil-Bermejo, "Datos sobre la Colegial de Olivares: las Reliquias", Arcbivo Hispa. lense, LXIX (1986), pp. 3-25.

7 A. Sancho Corbacho, Arquitectura barroca sevillana del siglo XVIII, Madrid, 1952, p. 155.

${ }^{8}$ A. Morales, "Las empresas artísticas del azzobispo don Luis de Salcedo y Azcona", Homenaje al Dr. Hernández Díaz, I, pp. 471-483.

${ }^{2} \mathrm{~L}$. Torres Balbás, "La Edad Media" en Resumen bistórico del urbamismo e\% España, segunda edicióts, Madrid, 1968, p. 91. 
integrador del edificio civil y el edificio religioso. Iglesia y palacio quedaban unidos por medio de pasadizos.

Felipe II en El Escorial subía al palacio situado en la cabecera del monasterio por un camino oculto en el muro. El antiguo Alcázar de Madrid -destruido por el incendio de 1734- era un prodigio de pasillos altos pegados a las paredes y que atravesaban las habitaciones, y que permitían los movimientos interiores del monarca sin ser visto por nadie, desembocando en escaleras "hurtadas" o secretas. Cuando la corte se instaló en Valladolid en 1601, ocupando el palacio de don Francisco de los Cobos, se adquirieron casas nobiliarias ubicadas en su entorno comunicándolas con el palacio por medio de pasadizos, algunos de los cuales se construyeron a ras del suelo, pero la mayoría de ellos fueron voladizos sobre arcos. ${ }^{10}$

Es claro que el pasadizo constituye la palmaria expresión de ese estado teocrático que se instaura en la monarquía española con la dinastía de los Austria. Aun cuando su función de vaso comunicante por el que pueda fluir el poder absoluto sin ser visto ni oído no necesite de la religión para justificarse, el hecho es que en los grandes conjuntos palacio-monasterio, palacio-colegiata, es donde alcanza su mayor elocuencia. Tal el caso del conjunto palacial de la villa de Lerma donde, a comienzos del siglo XVII, el valido don Francisco Gómez de Sandoval y Rojas, duque de Lerma, intentó emular la idea unitaria y centralizadora de Felipe II en El Escorial edificando palacio, convento y plaza con trazas de Francisco de Mora, "Arquitecto de Su Majestad", y el carmelita fray Alberto de la Madre de Dios, al tiempo que en término de menos de una década pobló el lugar de franciscanos, franciscanas, dominicos y carmelitas, en sus dos ramas, construyéndoles algo así como seis conventos. A través de un extenso circuito de pasadizos, el duque de Lerma podía pasar del palacio al próximo convento de las dominicas de San Blas sin bajar a la calle, del mismo modo que al de las carmelitas de Santa Teresa con sólo recorrer la larga galería que cerraba uno de los lados mayores de la plaza o también al de franciscanas de la Ascensión por medio de otro pasadizo que conectaba con el convento de las carmelitas, y a su vez, existía un último pasadizo que comunicaba a las franciscanas con la iglesia colegial de San Pedro, punto final del monacal itinerario. En suma, el señor Duque tenía acceso a los conventos de San Blas, Santa Teresa y la Ascensión que habia dotado ampliamente y traspasaba los dos últimos antes de llegar a la colegiata, que

$10 \mathrm{~J}$. J. Martín González, "Algunas peculiaridades del urbanismo español", Homenaje al Dr. Hernández Díaz, I, p. 465. Vid también G. Kubler, La obra del Escorial, Madrid, 1983, y J. Brown y J. Elliot, Un palacio para el rey. El Buen Retiro y la corte de Felipe IV, Madrid, 1982. 
DOI: http://dx.doi.org/10.22201/iie.18703062e.1988.59.1391

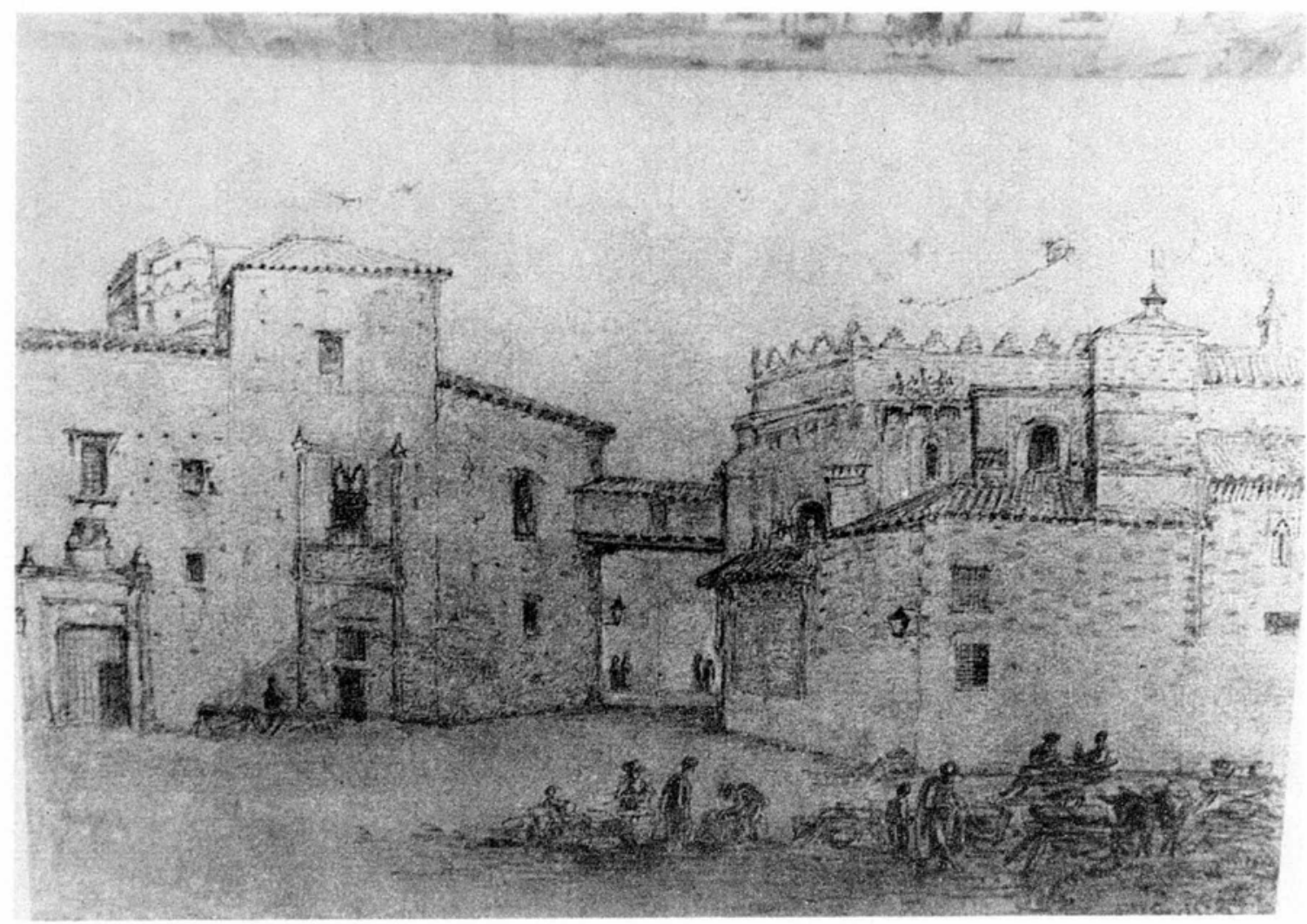

Figura 1. Palacio del Marqués de la Algaba. (Sevilla). 
DOI: http://dx.doi.org/10.22201/iie.18703062e.1988.59.1391

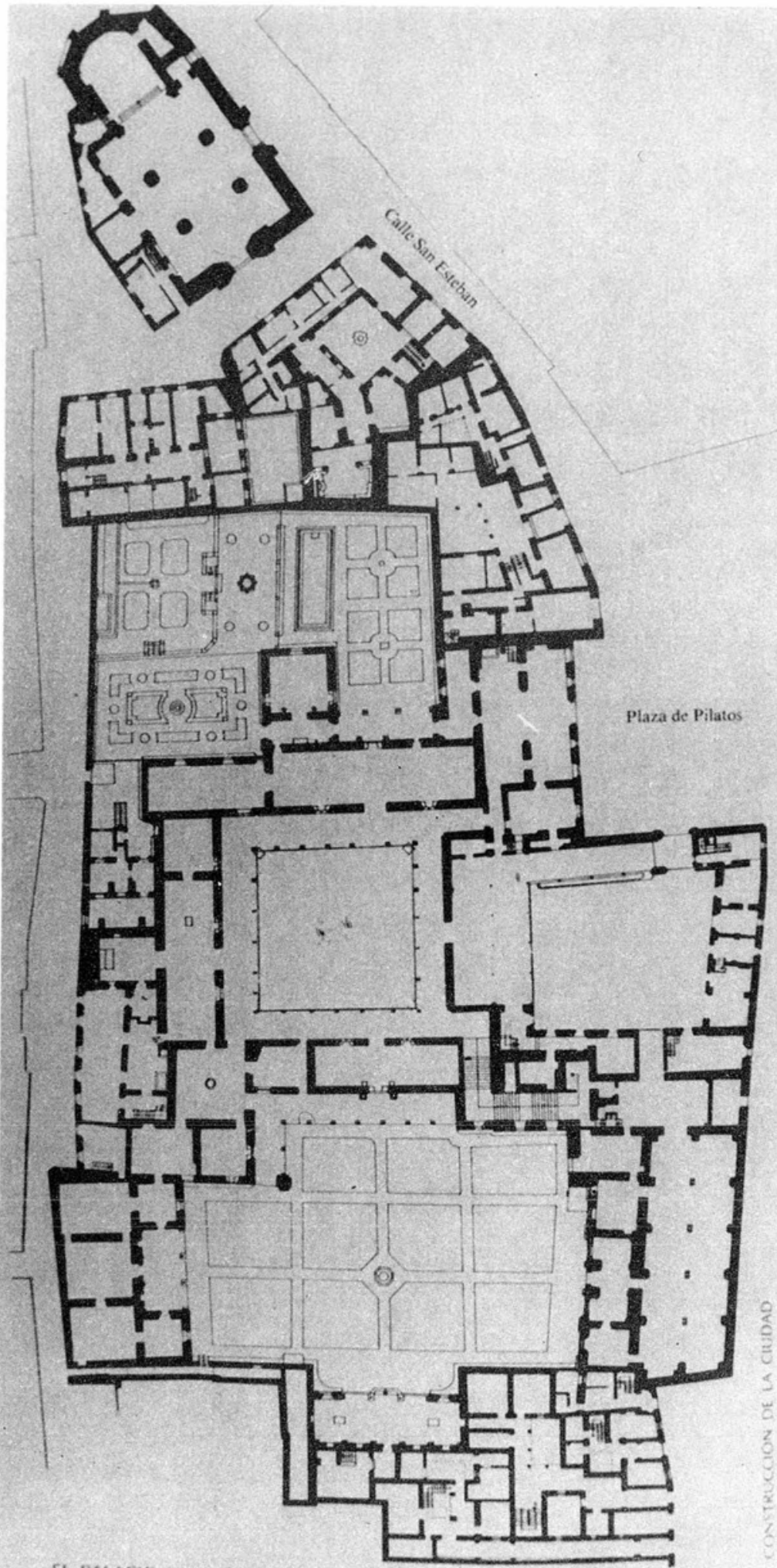

EL PALACIO Y UU ENTORNO

Figura 2. Casa de Pilatos. (Sevilla). 


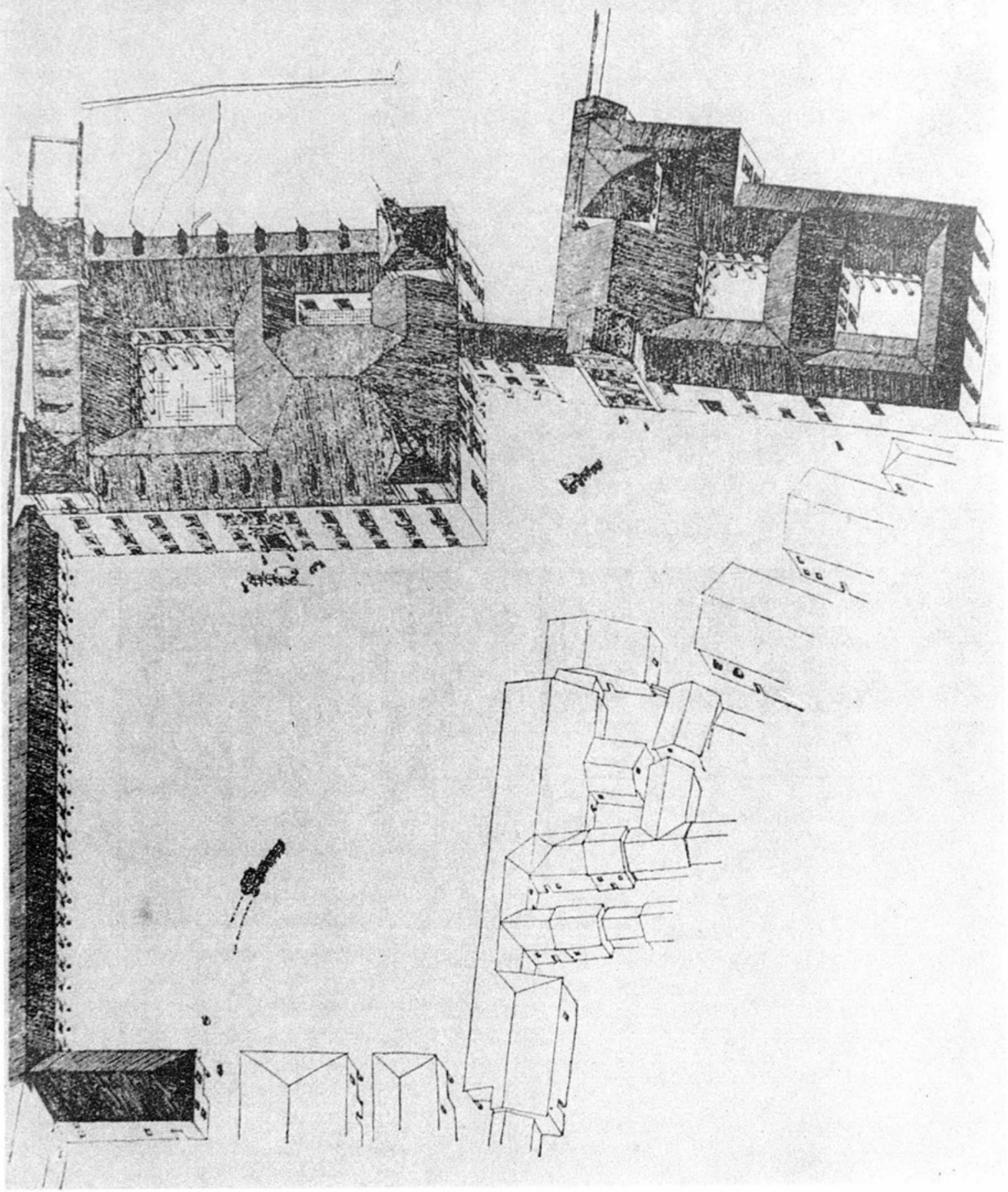

Figura 3. Plaza mayor de Lerma. (Burgos). 
DOI: http://dx.doi.org/10.22201/iie.18703062e.1988.59.1391

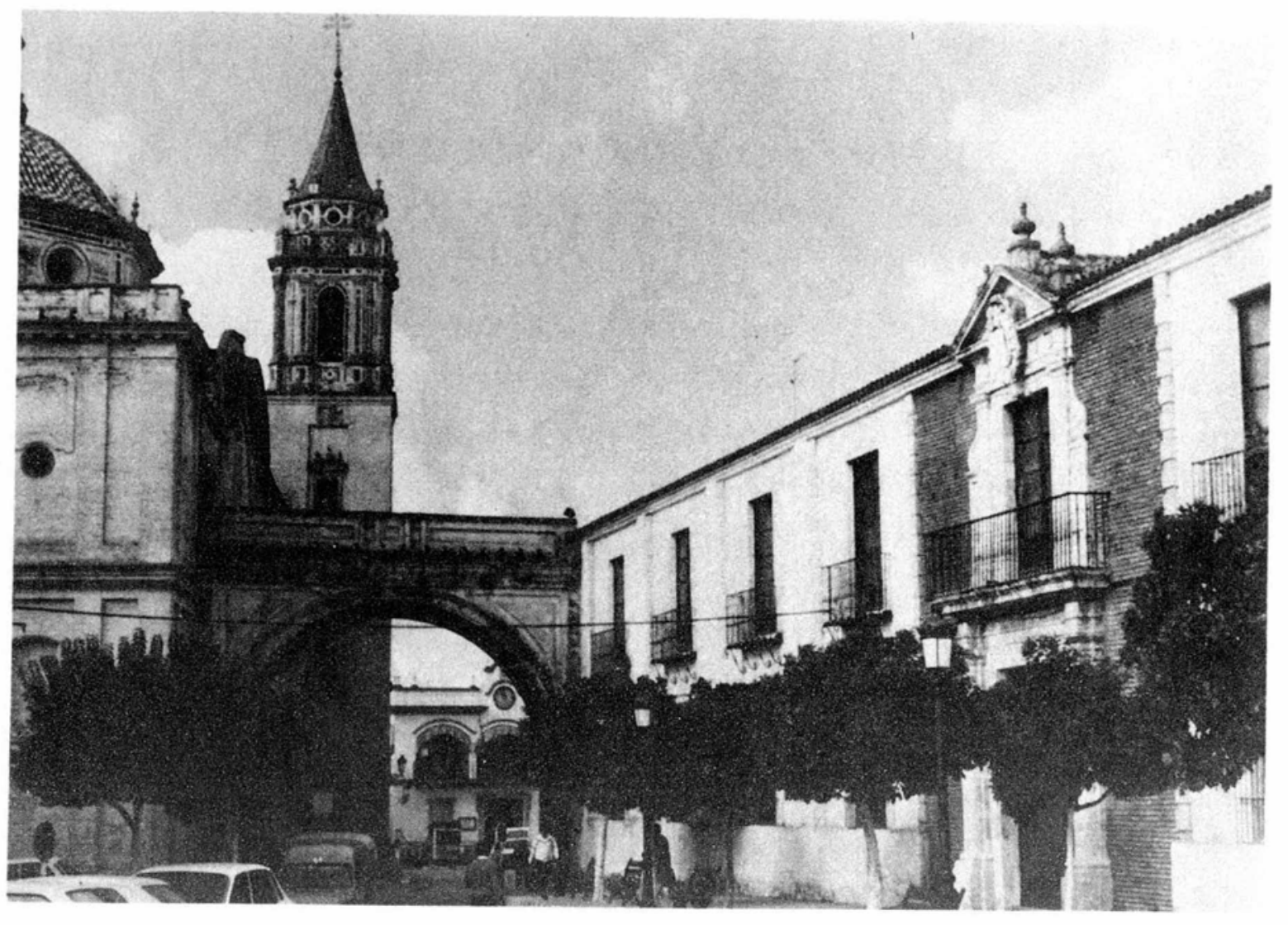

Figura 4. Palacio arzobispal de Umbrete. (Sevilla). 
también había fundado." En definitiva, el proyecto había consistido en unir el antiguo castillo - transformado en palacio y precedido de plaza mayor por obra y gracia de Francisco de Mora - con la pequeña iglesia de San Pedro - convertida ahora en magnífica colegiata - situada al otro extremo, por medio de una línea de edificios monacales femeninos que no venía a ser sino un prolongado y enorme pasadizo conventual que unía a la casa del duque con la casa de Dios.

$\mathrm{Si}$ miramos al exterior, podrían ponerse ciertas objeciones a nuestro argumento: $\mathrm{Y}$ nada menos que con un famoso ejemplo cual el "corridoio vasariano". Esta prolongada galería que enlaza los Uffizzi con el Palazzo Pitti, corriendo por encima de las tiendas del Ponte Vecchio y deteniéndose a mitad de camino en la iglesia de S. Felicità para que el espectador contemple el acrobático Descendimiento de Pontormo, tenía la finalidad de unir el palacio con las oficinas de la administración medicea al tiempo que permitía asistir a los oficios religiosos de la iglesia vecina. ${ }^{2}$ Pero la diferencia reside en que en Florencia la iglesia es un accidente en el camino de un punto a otro, no es algo buscado o propuesto como en Lerma, no es sustantiva sino adjetiva, no intrínseca al "corridoio" sino extrínseca y asimila$\mathrm{da}$, es decir, el Vasari la aprovecha porque queda en su camino.

Que el concepto de pasadizo está ligado a una ideología y que es producto de una mentalidad muy diferente, se evidencia cuando se consideran los ejemplos de otras ciudades italianas, en los que el Palazzo Ducale tiene su capilla dentro del propio recinto del palacio, como ocurre en Mantua, sin que exista esa obsesión por penetrar directamente al espacio sagrado a través del alambique del pasadizo.

El hecho de vivir el espacio conventual o eclesiástico y de que las familias reales establezcan su residencia dentro de los recintos monacales tiene larga tradición en la Península Ibérica; que arrancando de la monarquía asturiana se perpetúa en la Edad Media con ejemplos tan notables como el del monasterio de las Huelgas o el de Poblet, hasta llegar a los de Yuste y El Escorial, ${ }^{13}$ que pasman en piedra la idea del Estado teocrático moderno.

La forma obedece a la función. $Y$ en este caso la finalidad física responde a la intención política de intervenir en la esfera religiosa. El pasadizo nace de la necesidad de comunicar un lugar con otro aprovechando los ar-

"L. Cervera, "La época de los Austria" en Resumen bistórico del urbanismo en Espa. ña, pp. 188-191. Y del mismo autor, El conjunto palacial de la villa de Lerma, Valencia, 1977.

12 L. Benevolo, Diseño de la ciudad, III y IV, Barcelona, 1977.

13 F. Chueca Goitia, Casas Reales en monasterios y conventos españoles, Madrid, 1966. 
cos de las calles "encubiertas", que como tales se las menciona en las ordenanzas de Sevilla y Toledo cuando se refieren a los pisos altos o "sobrados" que atravesaban dichas calles. ${ }^{14}$ Según Covarrubias en el Tesoro de la lengua castellana o española (Madrid, 1611), "pasadizo es pontido que se haze en una calle para pasar de una casa a la otra", esto es "el passo u camino cubierto y estrecho, para passar de una parte aotra, regularmente abreviando". ${ }^{15}$

Abreviemos pues: el pasadizo, el puente que permitía unir, en muchos casos, el ámbito del poder civil con el religioso fue la expresión arquitectónica más plástica del binomio Iglesia-Estado de la España moderna.

14 Ordenanzas de Sevilla, Sevilla, 1632, cap. XXVI: "De los soberados que atrauiessan las calles, a que dizen encubiertas", f. 144 v. Vid. R. Cómez, Arquitectura Altonsi, Sevi1la, 1974, p. 73 y 117. El soberado era el piso alto al que los musulmanes denominaban algorfa, Cf. L. Torres Balbás, "Algunos aspectos de la casa hispano-musulmana: almace" rías, algorfas y saledizos", Al-Andalus, XV (1950), pp. 170-191.

${ }^{15} \mathrm{~F}$. García Salinero, Léxico de alarifes de los Siglos de Oro, Madrid, 1968, p. 174. 